\title{
Lipid mediators in plasma of autism spectrum disorders
}

Afaf El-Ansary ${ }^{1,3,4^{*}}$ and Laila Al-Ayadhi $i^{2,3,4}$

\begin{abstract}
Background: Inflammation is increasingly recognized as being of both physiological and pathological importance in the immature brain. Cerebellar pathology occurs in autism, as a neurodevelopmental disorder with genetic and environmental origins. The genesis of this disorder is still not understood but inflammation in utero or early in childhood is an environmental risk factor.

Methods: Prostaglandin E2 (PGE2), cysteinyl leukotriene as two important lipid mediators together with 8 isoprostane as marker of oxidative stress were measured using ELISA in plasma of 20 male autistic patients compared to 19 age and gender matching control participants.

Results: PGE2, leukotrienes and isoprostanes recorded significantly elevated levels in autistics compared to controls. Role of these measured parameters in inflammation and autoimmunity as two etiological factors in autism were discussed in details.

Conclusion: Receiver Operating Characteristic (ROC) curve analysis shows satisfactory values of area under the curve (AUC) which could reflect the high degree of specificity and sensitivity of the altered PGE2, leukotrienes and isoprostanes as predictive biomarkers in autistic patients from Saudi Arabia.
\end{abstract}

Keywords: Autism, Inflammation, Prostaglandins, Leukotrienes, Isoprostane, Arachidonic acid

\section{Background}

Autism spectrum disorders (ASDs) are currently one of the leading causes of developmental disability with approximately $1 \%$ children affected [1]. Etiologically, many different factors are involved. One of the most striking features of autism and other developmental disorders is that cognitive, social and sensory/motor development usually progress symptom free for several months to years but then is followed by a period of retardation where some skills fail to develop or do so but behind schedule, a period of regression where some acquired skills are lost, or a period of intrusion where acquired skills are overshadowed by the appearance of behaviors aberrant in form or frequency [2,3]. Importantly, the period when symptoms first begin to appear may represent the time when environmental toxicants have accumulated in the brain to critical levels and/or

\footnotetext{
* Correspondence: elansary@ksu.edu.sa

'Biochemistry Department, Science College, King Saud University, Riyadh, Saudi Arabia

${ }^{3}$ Autism Research and Treatment Center, Riyadh, Saudi Arabia

Full list of author information is available at the end of the article
}

the deleterious effects of earlier exposure may become manifest through perturbation of normal ontogenic development of brain pathways [4]. Furthermore, it is thought that certain individuals may be more sensitive to toxicants because of a genetic predisposition. Exposure during critical periods may disrupt neurobehavioral development by altering neural migration, circuitry, and/or synaptogenesis of brain areas required for expression of these behaviors [5]. A dysregulated immune response, accompanied by enhanced oxidative stress, abnormal mitochondrial metabolism, and impaired lipid metabolism seemingly represents the common molecular underpinning of certain neurodevelopmental disorders among which is autism spectrum disorders (ASD). Understanding and confirming the role of these pathways in the aetiology of autism are important for the definition of pharmacological therapies able to ameliorate clinical symptoms [6-8]. Most recently, the strongest evidence was given for immune dysregulation/ inflammation and oxidative stress, followed by toxicant exposures and mitochondrial dysfunction as trends
C Biomed Central

(C) 2012 El-Ansary and Al-Ayadhi; licensee BioMed Central Ltd. This is an Open Access article distributed under the terms of the Creative Commons Attribution License (http://creativecommons.org/licenses/by/2.0), which permits unrestricted use,

distribution, and reproduction in any medium, provided the original work is properly cited. 
in physiological abnormalities in autism spectrum disorders [9].

Arachidonic acid (AA) is metabolized by means of two pathways: cyclooxygenase, leading to the formation of prostaglandins, and lipoxygenase, leading to the production of leukotrienes. Their concentrations are reportedly increased in brain injury [10] and is directly related to the increase of blood-brain barrier (BBB) permeability [11].

Prostaglandin E2 (PGE2) is a compound derived from membrane phospholipids and an important mediator of synaptic plasticity, pain response, sleep/ awake cycle and is believed to be associated with inflammation in the brain [12-15]. Both stimulant and depressant effects of PGs on the CNS have been reported following their injection into the cerebral ventricle and the firing rates of individual brain cells may be increased or decreased after iontrophoric applications of PGs [16]. PGs have been proposed to modulate catecholaminergic [17], serotoninergic [18] and cholinergic [19] neurons in the CNS. There is also accumulating data suggesting possible modulatory role of PGs on dopamine mediated behavior [20].

Several in vitro markers of oxidative stress are available, but most are of limited value in vivo because they lack sensitivity and/or specificity or require invasive methods [16]. Isoprostanes are prostaglandin (PG) -like substances that are produced in vivo independently of cyclooxygenase (COX) enzymes, primarily by free radical- induced peroxidation of arachidonic acid [21]. Oxidation of docosahexaenoic acid, an abundant unsaturated fatty acid in the central nervous system, results in the formation of isoprostane-like compounds, termed neuroprostanes [22].

Convincing experimental data indicate that PGs function in mostly pathological processes in the CNS, including, fever induction, learning and memory, and excitotoxic brain injury such as stroke, epilepsy [23]. Tamiji and Crawford [24] recorded deficits associated with the release of arachidonic acid from membrane phospholipids and its subsequent metabolism to PGs in ASD. This was supported by a more recent study in which impaired fatty acids profile and decreased concentrations of Phosphatidylserine (PS), Phosphatidylcholine (PC), and Phosphatidylethanolamine (PE) were recorded in autistic patients compared to healthy controls [25]. This information motivate our interest to measure PGE2, cysteinyl leukotriene and 8-isoprostane in plasma of autistic patients in a trial to investigate the role of these lipid mediators related to AA and Phospholipids (PS, PC and $\mathrm{PE}$ ) in the pathology of autism.

\section{Methods}

\section{Reagents and chemicals}

Ethyl acetate and potassium hydroxide used for extraction of 8 isoprostane were of analytical grade and obtained from Sigma-Aldrich (Taufkirchen, Germany).

\section{Participants and methods}

The study protocol followed the ethical guidelines of the most recent Declaration of Helsinki (Edinburgh, 2000). All subjects enrolled in the study (20 autistic males and 19 control males) had written informed consent provided by their parents and assented to participate if developmentally able. They were enrolled through the ART Center (Autism Research \& Treatment Center) clinic. The ART Center clinic sample population consisted of children diagnosed on the autism spectrum disorder (ASD). The diagnosis of ASD was confirmed in all subjects using the Autism Diagnostic Interview-Revised (ADI-R) and the Autism Diagnostic Observation Schedule (ADOS) and 3DI (Developmental, dimensional diagnostic interview). The ages of all autistic children participated in the study were between 4-12 years old. All were simplex cases. All are negative for fragile $\mathrm{x}$ gene study. The control group recruited from well baby clinic at king Khaled university hospital with mean age 4-11 years old. Subjects were excluded from the investigation if they had dysmorphic features, or diagnosis of fragile $\mathrm{X}$ or other serious neurological (e.g., seizures), psychiatric (e.g., bipolar disorder) or known medical conditions. All participants were screened via parental interview for current and past physical illness. Children with known endocrine, cardiovascular, pulmonary, liver, kidney or other medical disease were excluded from the study.

\section{Samples collection}

Blood samples were collected in the morning following at least 10 hour period of fasting. Plasma was collected using standard clinical practices and stored at $-80^{\circ} \mathrm{C}$ until thawed for analysis.

\section{Assay of 8-Isoprostane}

8 isoprostane was extracted and saponified from plasma of autistic and control participants using ethyl acetate and potassium hydroxide $(\mathrm{KOH})$. The aqueous solution was diluted using dilution buffer and 8 isoprostane then was measured using ELISA kit, product of Detroit $\mathrm{R}$ and $\mathrm{D}$, Inc according to the instructions of the manufacturer. The plate was read at $450 \mathrm{~nm}$ together with serial concentrations of standard.

\section{Assay of PGE2}

PGE2 was measured using a diagnostic kit, a product of Uscn, Life Science Inc, USA. This assay employs the competitive inhibition enzyme immunoassay technique in which a microplate was pre-coated with monoclonal antibody specific for human PGE2. A competitive inhibition reaction is launched between biotin labeled human PGE2 and unlabeled human PGE2 (Standards or samples) with the pre-coated antibody specific for human PGE2. After incubation the unbound conjugate 
is washed off. After washing, avidin conjugated to Horseradish peroxidase (HRP) is added to each microplate well and incubated. The amount of bound HRP conjugate is reverse proportional to the concentration of PGE2 in the sample. After addition of the substrate solution, the intensity of colour developed is reverse proportional to the concentration of PGE2 in the sample. The minimum detectable concentration of PGE2 is typically less than $10.79 \mathrm{pg} / \mathrm{ml}$.

\section{Assay of cysteinyl leukotriene}

Cysteinyl leukotriene was measured in plasma of autistic patients using a non-radioactive, safe ELISA kit, a product of Enzo life Science. The coated well immuno-enzymatic assay for the quantitative measurement of LTC4 /D4 /E4 utilizes a multi-clonal anti-LT antibody and a LT- HRP conjugate. The intensity of colour is measured spectrophotometrically at $405 \mathrm{~nm}$ in a microplate reader and it is inversely proportional to the LT concentration. The detection limit range is $78.1-2500 \mathrm{pg} / \mathrm{ml}$ and sensitivity in this assay is $26.6 \mathrm{pg} / \mathrm{ml}$.

\section{Statistical analysis}

An SPSS computer program was used. Results were expressed as mean \pm S.D. and all statistical comparisons were made by means of independent $\mathrm{t}$-Test with $\mathrm{P} \leq 0.005$ was considered significant. Receiver Operating Characteristics analysis (ROC) was performed. Area under the curve, cut off values together with degree of specificity and sensitivity were calculated. ROC curves are constructed by plotting the false positive rate (i.e. 100specificity) against the true positive rate (i.e. sensitivity).

These have been widely accepted as standard tools for evaluating the performance of diagnostic tests. The AUC is an overall summary of diagnostic accuracy, incorporating both components of accuracy, i.e., sensitivity and specificity, into a single measure. The AUC has been widely used as a quantitative index of the performance of a biomarker in a variety of applied fields; it is a simple and convenient overall measure of diagnostic test [26].

\section{Results}

Results are presented as Mean \pm S.D. of 8- isoprostane, leukotriene and PGE2 of 20 autistic patients and 19 age and gender-matching controls. It could be easily noticed that the three measured parameters were significantly higher in autistic patients, recording an increase of 45.65, 90.9 and $91.15 \%$ for 8- isoprostane, leukotriene and PGE2 respectively (Table 1 and Figure 1 ).

Figures $(2,3,4)$ present the normal distribution of the measured parameters. Figure 2 demonstrates that 12/20 of autistic patients recorded isoprostane levels higher than $100 \mathrm{pg} / \mathrm{ml}$, while $8 / 20$ recorded values greater than
Table 1 Levels of 8-isoprostane, leukotrienes and PGE2 in plasma of autistic patients compared to healthy controls

\begin{tabular}{lllll}
\hline Parameters & Groups & N & Mean \pm S.D. & P value \\
\hline Isoprostanes $(\mathrm{pg} / \mathrm{ml})$ & Control & 19 & $68.27 \pm 10.00$ & 0.001 \\
\cline { 2 - 4 } & Autistic & 20 & $99.42 \pm 10.76$ & \\
\hline Leukotriene $(\mathrm{pg} / \mathrm{ml})$ & Control & 19 & $190.42 \pm 15.27$ & 0.001 \\
\cline { 2 - 4 } & Autistic & 20 & $363.62 \pm 43.12$ & \\
\hline PGE2 $(\mathrm{pg} / \mathrm{ml})$ & Control & 19 & $217.97 \pm 30.00$ & 0.001 \\
\cline { 2 - 4 } & Autistic & 20 & $416.64 \pm 31.52$ & \\
\hline
\end{tabular}

$85 \mathrm{pg} / \mathrm{ml}$ as the maximum concentration in control subjects. $18 / 20$ of control subjects, recorded isoprostane levels lower than $85 \mathrm{pg} / \mathrm{ml}$. Figure 3 shows that 20/20 of autistic patients recorded leukotriene levels higher than $280 \mathrm{pg} / \mathrm{ml}$ compared to a remarkable lower value less than $200 \mathrm{pg} / \mathrm{ml}$ in 15/19 of control subjects. Figure 4 shows that lower level of PGE2 in autistic patients $(360 \mathrm{pg} / \mathrm{ml})$ was much greater than the highest concentration in control $(280 \mathrm{pg} / \mathrm{ml})$.

Table 2 and Figure 5 demonstrate the Pearson correlations between the three measured parameters. It could be easily seen that 8-isoprostane, leukotrienes and PGE2 are positively correlated with $\mathrm{P}$ values $<0.001$. Table 3 together with Figure 6 show the ROC analysis of the measured parameters. Area under the curve, specificity and sensitivity together with the best cut off values.

\section{Discussion}

The demonstration of oxidation of membrane phospholipids (PL) led to a new fruitful era with a continuous flow of considerable research devoted to chemistry, biochemistry and medicine [27]. Hydroperoxides derived from AA serve as modulators of the enzymes involved in the biosynthesis of prostaglandins and leukotrienes [28-30]. It is well known that non-enzymatic free radicalinduced cyclooxygenation of AA and its phospholipid esters through the isoprostane pathway gives rise to

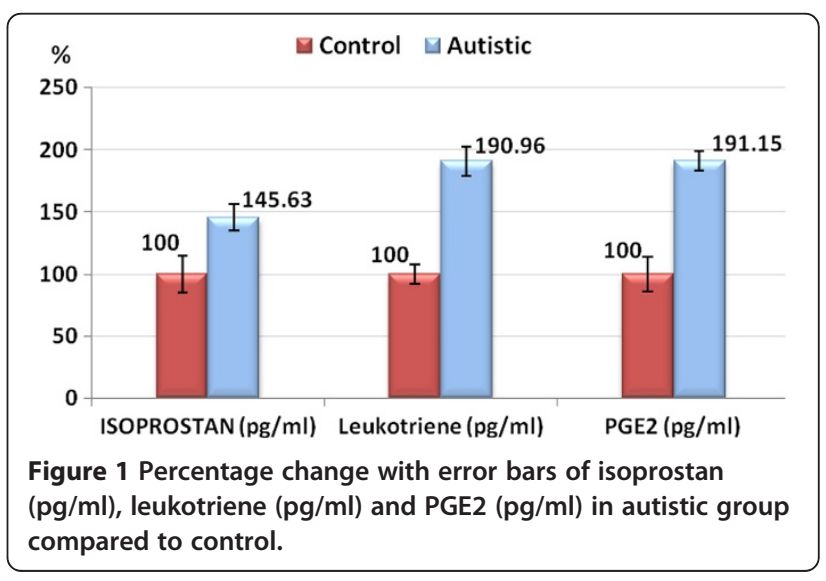




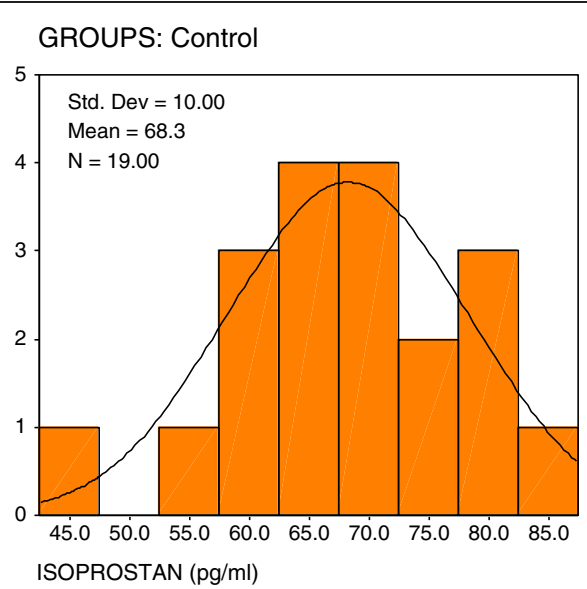

GROUPS: Autistic

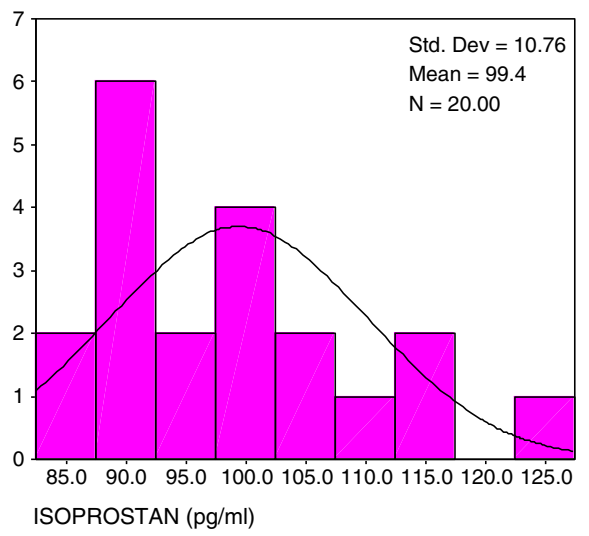

Figure 2 Normal distribution for control and autistic groups in isoprostan (pg/ml).

four structurally isomeric families of phospholipid endoperoxide stereoisomers of PGs which were coined isoprostanes (isoPs) [21,27]. As electrophils, isoprostanes have exceptional reactivity to biological nucleophiles such as proteins and DNA [31].

In the present study, the remarkable increase of isoprostanes in plasma of Saudi autistic patients compared to healthy controls (Table 1 ), could be easily related to the oxidative stress as an accepted mechanism in the etiology of autism. This suggestion could be supported through considering the previous work of Ming et al. [32] in which they recorded urinary excretion of 8-isoprostane (8-iso-PGF2a) a class of autoxidation products generated from AA acid by a free radical initiated process, in children with autism compared to age-matched controls. Both finding are consistent with the recent work of El-Ansary et al. [33] in which they proved that autistic patients from Saudi Arabia have significantly lower level of AA and suggested impaired fatty acid profile as a diagnostic marker of autism. Elevated plasma and urinary isoprostans together with the diminished level of AA could be related to the impaired inflammatory responses seen in autistic patients [34].

The contribution of isoprostane- related oxidative injury to autism was explored by autoimmunity as an etiological factor of autism [35]. Autoimmunity, an abnormal immune reaction in which the immune system becomes primed to react against body organs. It can result from an immune response against altered self proteins, e.g., modified by adduction of lipid-derived electrophiles generated by oxidative injury. IgG, IgA , IgM and myelin basic protein anti-brain auto antibodies were present in high percentage of sera from children with autism compared to healthy children [36]. Nine neuronspecific antigens, three encephalitogenic and microfilaments were among the autoimmune-attacked proteins. The possible operation of an immune response against altered self proteins in autism was demonstrated by $\mathrm{Lu}$ [35]. The occurrence of 2-pentylpyrrole, iso [3] LGE2protein adducts and carboxyethylpyrrole (CEP) protein
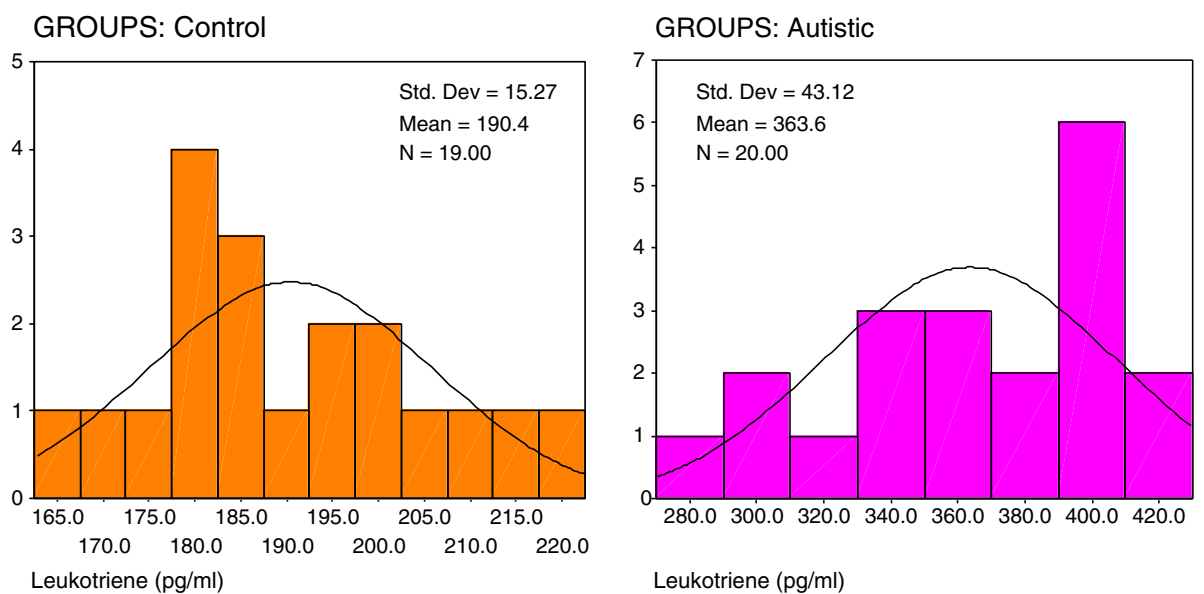

Figure 3 Normal distribution for control and autistic groups in Leukotriene (pg/ml). 

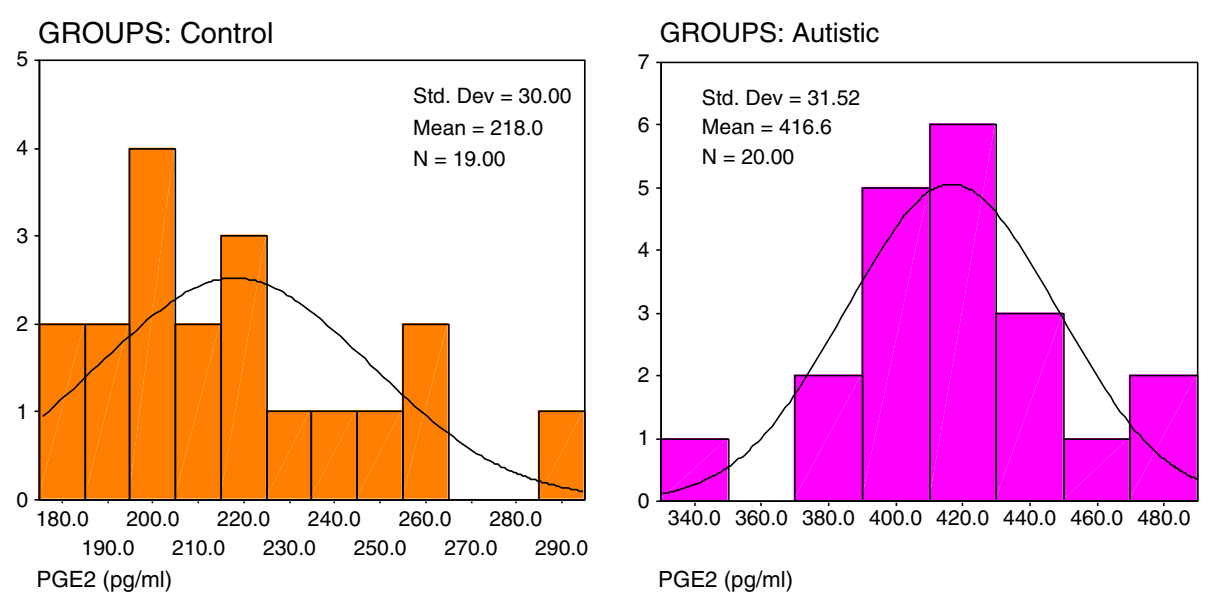

Figure 4 Normal distribution for control and autistic groups in PGE2 (pg/ml).

modifications in brain and blood from autistic individuals was proved $[37,38]$.

Moreover, immunohistochemical analysis of brain tissues such as cerebellum, hippocampus and neocortical regions has shown significant CEP-staining and iso [3] LGE2-protein adduct in the white matter in every autistic cases compared to control age-matched cases which suggest elevated oxidative damage in these brain regions in autism [27].

It has been recognized for many years that leukotrienes play an important role in mediating various effects of the allergic reaction. Recent evidence has shown that they play a role in many diseases. Leukotrienes can be separated into the fairly well characterized cysteinyl leukotrienes and less well characterized leukotriene B. Effects of the leukotrienes are mediated through receptors that are expressed on a variety of cell types and can be modulated based on the inflammatory environment present [39]. Human 5-lipoxygenase (5-LOX) is one of the key anti-inflammatory drug targets due to its key role in leukotrienes biosynthesis which show that leukotrienes [40] and low-grade inflammation might be a common denominator of some psychiatric diseases as major and postpartum depression, schizophrenia, and autism [41]. The long-chain polyunsaturated fatty acids (LCPUFA) ecosapentanoic (EPA), docosahexaenoic acid (DHA) and $\mathrm{AA}$ are intimately related to the initiation and resolution of inflammatory responses proved in the present study. El-Ansary et al. [33] proved that the balance between AA and EPA + DHA is disturbed in Saudi autistics. Higher DHA/AA, EPA/AA and EPA/DHA in plasma of Saudi autistics could be easily related to the recorded elevation of PGE2 and leukotrienes (Table 1), as lipid mediators involved in the pathophysiology of autism. The significant elevation of PGE2 in autistic patients compared to agematched control participants could be related to glutamate exitotoxicity [42], lower GABA [8] and autistic amygdala lesion as factor related to the social abnormalities in autism [43]. Lozinsky [44] proved that PGE2 alter intracellular $\mathrm{Ca}^{2+}$ homeostasis, glutamate release and activation of transcription factors. PGE2 increase the release of intracellular $\mathrm{Ca}^{2+}$ stores, with some entry of extracellular calcium. This in turn could induce glutamate release from astrocytes leading to abnormal neuron-astrocyte interaction. Since elevated glutamate is coupled with decreased GABA due to decreased glutamic acid decarboxylase (GAD) protein expression in partial and cerebellar cortex of brain of autistic individuals, so elevated PGE2 reported in the present study could be related to the reduced GABA level previously recorded in Saudi autistic patients compared to control [8].

Elevated prostaglandins could be related to the recent record of Rossignol and Frye [9] that immune dysregulation/ inflammation are the first etiological factor of autism. It is well known that autism could be associated with viral infections [45], which cause an up regulation in prostaglandins that then mediate fever production. This suggestion could support the elevated inflammatory cytokines in the plasma $[7,46]$ and brains of autistic patients $[47,48]$.

The profound effect of gonadal steroids on the developing brain to produce sex differences in physiology and

Table 2 By using statistical analysis program (SPSS) which includes the pearson correlation test, the correlation was done between all parameters; the results showed that there was a significant correlation difference between the following parameters

\begin{tabular}{lccc}
\hline Parameters & R (Pearson Correlation) & Sig. & \\
\hline Isoprostan $\sim$ Leukotriene & 0.777 & 0.001 & $\mathrm{P}^{\mathrm{a}}$ \\
\hline Isoprostan $\sim$ PGE2 & 0.820 & 0.001 & $\mathrm{P}^{\mathrm{a}}$ \\
\hline Leukotriene $\sim$ PGE2 & 0.926 & 0.001 & $\mathrm{P}^{\mathrm{a}}$
\end{tabular}

a Positive Correlation. 

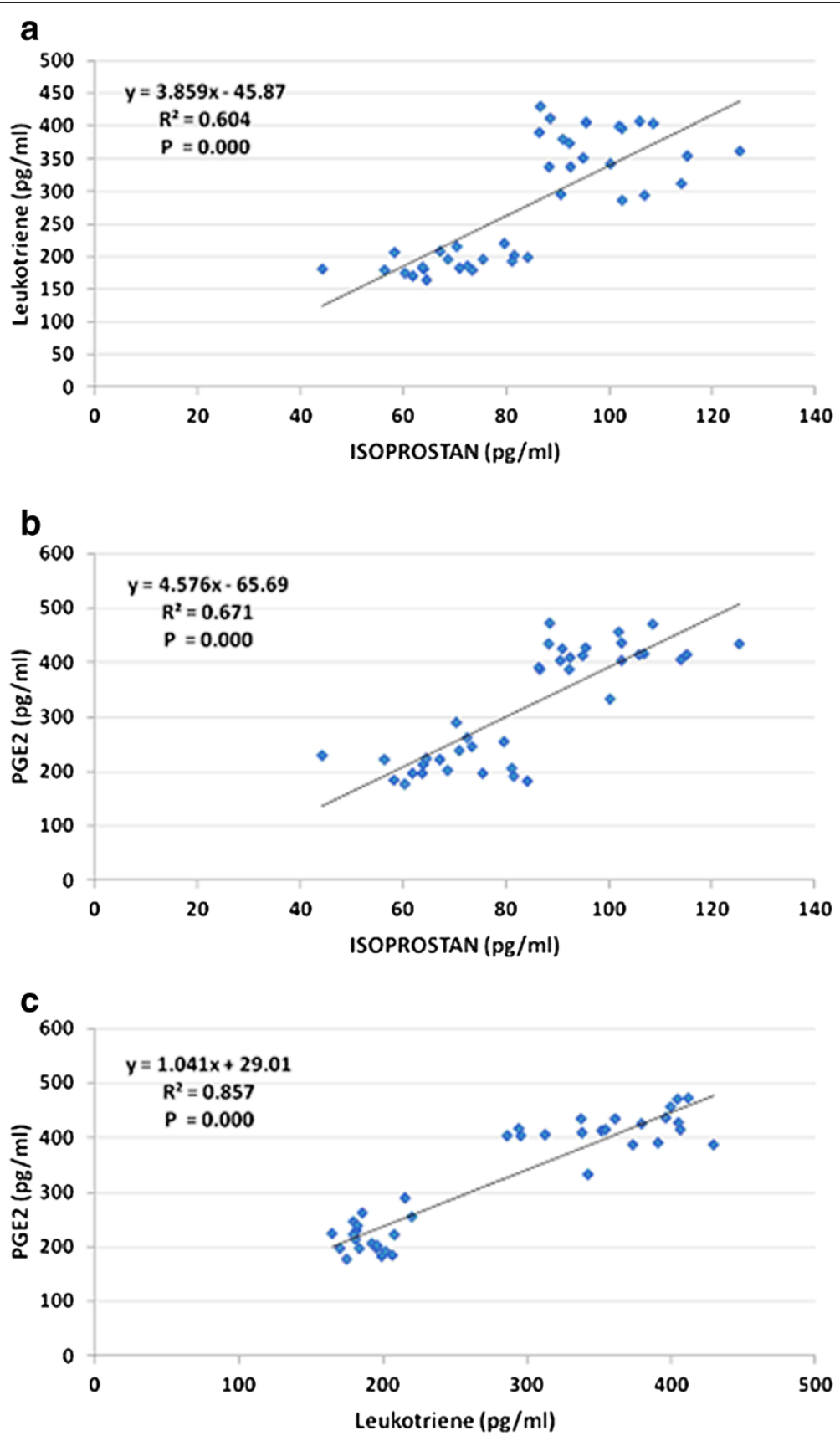

Figure 5 Pearson correlations between the three measured parameters with the best fit line.

Table 3 ROC analysis of the three measured parameters

\begin{tabular}{lcccc}
\hline Parameter & $\begin{array}{c}\text { Area under the } \\
\text { curve }\end{array}$ & $\begin{array}{c}\text { Cutoff } \\
\text { value }\end{array}$ & $\begin{array}{c}\text { Sensitivity } \\
\%\end{array}$ & $\begin{array}{c}\text { Specificity } \\
\%\end{array}$ \\
\hline Isoprostan & 1.000 & 78.270 & $100.0 \%$ & $78.9 \%$ \\
\hline Leukotriene & 1.000 & 205.689 & $100.0 \%$ & $84.2 \%$ \\
\hline PGE2 & 1.000 & 247.968 & $100.0 \%$ & $84.2 \%$ \\
\hline
\end{tabular}

behaviour suggests steroids may also be an important source of sex differences in neuropathology. While the causes of autism are unknown, several environmental factors are suspected. The "extreme male brain" theory of autism states that excessive prenatal androgens push brain development beyond the range of the normal male and causes a pathological level of hypersensitivity, hyposociality, extreme focus and disordered thoughts $[49,50]$. It has been shown that children with autism have significantly elevated androgen levels and that anti-androgen 

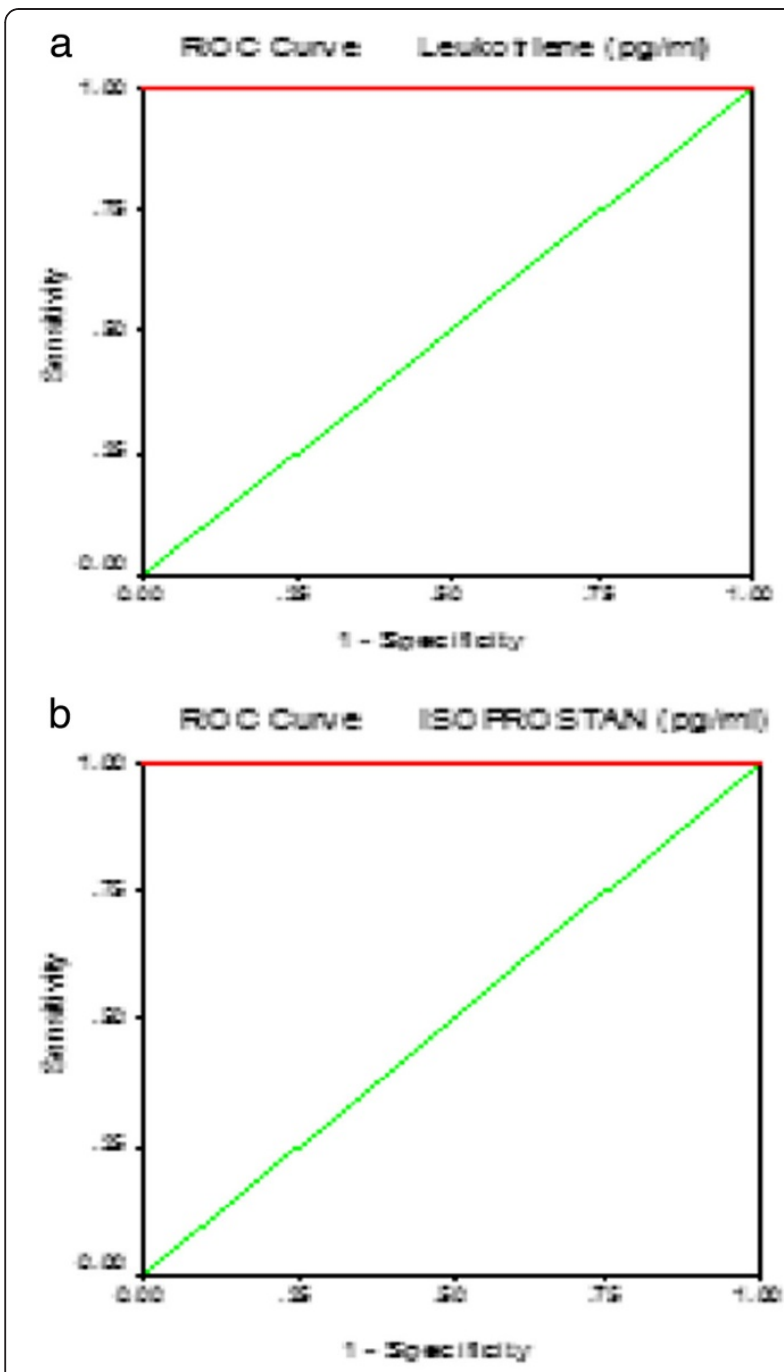

C FOC Cuwe PGE2 (pgml)

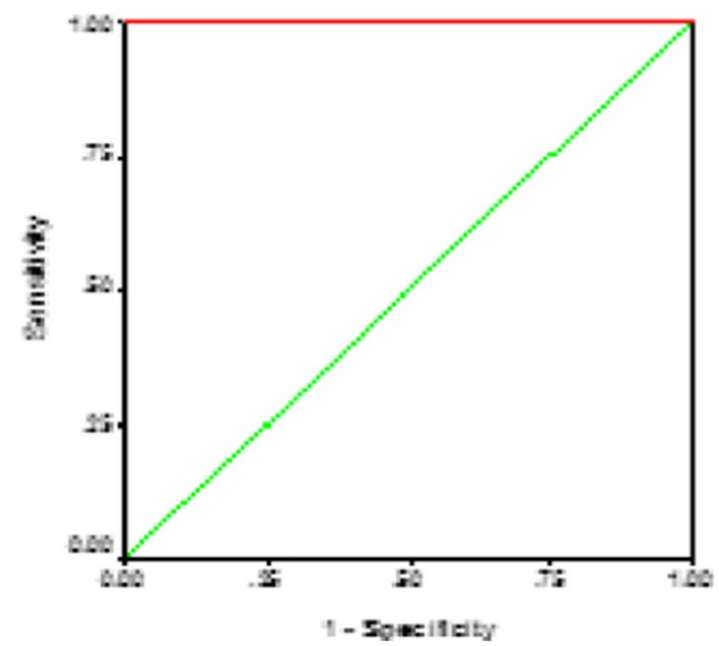

Figure 6 ROC Curve of isoprostan (a)leukotriene (b) and PGE2 (c) in autistic group. therapy may be of benefit in some autistic patients [51-53]. Testosterone is the immediate precursor of estradiol, which is formed via aromatization. The connection between prostaglandins and estradiol regulation which was uncovered by Dean [54] indicate the role of both in the common pathway of cerebellar development and that disruption of each could be related to the risk of manifesting autism later in life. Higher PGE2 reported in the present study could lead and reflect disruption of estradiol level through activation of aromatase enzyme, which could explain the sex differences in autism prevalence.

The significant positive correlations recorded between 8-isoprostan, Leukotriene and PGE2 (Table 2 and Figure 5), confirmed the association between the impairment of LCPUFA metabolism together with proinflammation and oxidative stress in the etiopathology of autism. The high specificity and sensitivity recorded for the three measured parameters could help to list 8 -isoprostan, Leukotriene and PGE2 among predictive biomarkers usually used to predict outcome to a specific treatment. This study could help to suggest omega-3 LCPUFA supplementation as a strategy for the early intervention to ameliorate pro-inflammation and oxidative stress related symptoms in autism. However, further research is required before definitive recommendations can be made about the routine use of omega- 3 fatty acids in treating autistic patients [55].

\section{Competing interests}

The author(s) declare that they have no competing interests.

\section{Authors' contributions}

El-A: Designed the work, performed the analysis and drafted the manuscript. Al-A: Diagnosis of the autistic patients and provision of blood samples of all participants. All authors read and approved the final manuscript.

\section{Acknowledgements}

The authors would like to thank Shaik AL-Amodi Autism Research Chair, NPST - Medical Centers and the parents of autistic children, without whom this work was not possible. This work was supported by King Abdul Aziz City for Science and Technology (KACST).

\section{Author details}

'Biochemistry Department, Science College, King Saud University, Riyadh, Saudi Arabia. ${ }^{2}$ Department of Physiology, Faculty of Medicine, King Saud University, Riyadh, Saudi Arabia. ${ }^{3}$ Autism Research and Treatment Center, Riyadh, Saudi Arabia. ${ }^{4}$ Shaik AL-Amodi Autism Research Chair, King Saud University, Riyadh, Saudi Arabia.

Received: 6 June 2012 Accepted: 26 October 2012 Published: 21 November 2012

\section{References}

1. Centers for Disease Control and Prevention (CDC): Prevalence of autism spectrum disorders - Autism and Developmental Disabilities Monitoring Network, United States, 2006. MMWR Surveill Summ 2009, 58(10):1-20.

2. Ozonoff S, losif AM, Baguio F, et al: A prospective study of the emergence of early behavioral signs of autism. J Am Acad Child Adolesc Psychiatry 2010, 49(3):256-266.

3. Ozonoff S, Heung K, Byrd R, Hansen R, Hertz-Picciotto I: The onset of autism: patterns of symptom emergence in the first years of life. Autism Res 2008, 1(6):320-328. 
4. Hussain J, Woolf AD, Sandel M, Shannon MW: Environmental evaluation of a child with developmental disability. Pediatr Clin North Am 2007, 54(1):47-62

5. Kalkbrenner AE, Daniels JL, Chen JC, Poole C, Emch M, Morrissey J: Perinatal exposure to hazardous air pollutants and autism spectrum disorders at age 8. Epidemiology 2010, 21(5):631-641.

6. Lintas C, Sacco R, Persico AM: Genome-wide expression studies in autism spectrum disorder, Rett syndrome, and Down syndrome. Neurobiol Dis 2012, 45(1):57-68.

7. El-Ansary AK, Ben Bacha AG, Al-Ayadhi LY: Proinflammatory and proapoptotic markers in relation to mono and di-cations in plasma of autistic patients from Saudi Arabia. J Neuroinflammation 2011, 8:142.

8. El-Ansary AK, Ben Bacha AG, Al-Ayadhi LY: Relationship between chronic lead toxicity and plasma neurotransmitters in autistic patients from Saudi Arabia. Clin Biochem 2011, 44(13):1116-1120.

9. Rossignol DA, Frye RE: A review of research trends in physiological abnormalities in autism spectrum disorders: immune dysregulation, inflammation, oxidative stress, mitochondrial dysfunction and environmental toxicant exposures. Mol Psychiatry 2012, 17:389-401.

10. Schuhmann MU, Mokhtarzadeh M, Stichtenoth DO, et al: Temporal profiles of cerebrospinal fluid leukotrienes, brain edema and inflammatory response following experimental brain injury. Neurol Res 2003, 25(5):481-491.

11. Black KL, Hoff JT: Leukotrienes Increase Blood-brain Barrier Permeability Following Intraparenchymal Injections in Rats. Ann Neurol 1985, 18(3):349-351.

12. Sang N, Chen C: Lipid signaling and synaptic plasticity. Neuroscientist 2006, 12(5):425-434.

13. Chen C, Bazan NG: Lipid signaling: sleep, synaptic plasticity and neuroprotection. Prostaglandins Other Lipid Mediat 2005, 77(1-4):65-76.

14. Hein AM, O'Banion MK: Neuroinflammation and memory: the role of prostaglandins. Mol Neurobiol 2009, 40(1):15-32.

15. Leger DF, et al: Prostaglandins E2 at new glance: Novel insights in functional diversity offer therapeutic chances. Int J Biochem Cell Biol 2010, 42(2):198-201.

16. Roberts $L J$, Morrow JD: Measurement of F2-isoprostanes as an index of oxidative stress in vivo. Free Radic Biol Med 2000, 28:505-513.

17. Narumiya S, Ogorochi T, Nakao K, Hayaishi O: Prostaglandin D2 in the rat brain, spinal cord and the pituitary: basal level and regional distribution. Life Science 1982, 31:2093-2103.

18. Brus R, Herman ZS, Szkilnik R, Zabawska J: Mediation of central prostaglandin effects by serotoninergic neurons. Psychopharmacology 1979, 64:116-120.

19. Saito R, Kamiya $H$, Ono N: Role of central muscarinic receptor of prostaglandin 12 in cardiovascular function in rat. Brain Res 1985, 330:167-169.

20. Naidu PS, Kulkarni SK: Differential effects of cyclooxygenase inhibitors on haloperidolinduced catalepsy. Prog Neuropsychopharmacol Biol Psychiatry 2002, 26:819-822.

21. Morrow JD, Hill KE, Burk RF, Nammour TM, Badr KF, Roberts $L J$ 2nd: A series of prostaglandin F2-like compounds are produced in vivo in humans by anon-cyclooxygenase, free radical-catalyzed mechanism. Proc Natl Acad Sci USA 1990, 87(23):9383-9387.

22. Hardy ARP, Chemtob S, Detbarn WD, Morrow JD: Formation of isoprostane-like compounds (neuroprostanes) in vivo from docosahexaenoic acid. J Biol Chem 1998, 273:13605-13612

23. Ito S, Okuda-Ashitaka E, Minami T: Central and peripheral roles of prostaglandins in pain and their interactions with novel neuropeptides nociceptin and nocistatin. Neurosci Res 2001, 41(4):299-332.

24. Tamiji J, Crawford DA: The neurobiology of lipid metabolism in autism spectrum disorders. Neurosignals 2010, 18(2):98-112.

25. El-Ansary AK, Bacha AG, Al-Ayahdi LY: Impaired plasma phospholipids and relative amounts of essential polyunsaturated fatty acids in autistic patients from Saudi Arabia. Lipids Health Dis 2011, 22:10-63.

26. Pepe MS, Feng Z, Huang $Y$, et al: Integrating the predictiveness of a marker with its performance as a classifier. Am J Epidemiol 2008, 167(3):362-368.

27. Evans TA, Siedlak SA, Lu L, et al: The autistic phenotype exhibits a remarkably localized modification of brain protein by products of free radical-induced lipid oxidation. Am J Biochem Biotechnol 2008, 4:61-72.
28. Salomon RG, Subbanagounder G, Singh U, O'Neil J, Hoff HF: Oxidation of low-density lipoproteins produces levuglandin-protein adducts. Chem Res Toxicol 1997, 10(7):750-759.

29. Boutaud O, Brame CJ, Salomon RG, Roberts $L J$ 2nd, Oates JA: Characterization of the lysyl adducts formed from prostaglandin $\mathrm{H} 2$ via the levuglandin pathway. Biochemistry 1999, 38(29):9389-9396.

30. Murthi KK, Friedman LR, Oleinick NL, Salomon RG: Formation of DNAprotein cross-links in mammalian cells by levuglandin E2. Biochemistry 1993, 32(15):4090-4097.

31. Salomon RG: Levuglandins and isolevuglandins: stealthy toxins of oxidative injury. Antioxid. Redox. Signal 2005, 7(1-2):185-201.

32. Ming X, Stein TP, Brimacombe M, Johnson WG, Lambert GH, Wagner GC: Increased excretion of lipid peroxidation biomarker in autism. Prostaglandins Leukot Essent Fatty Acids 2005, 73(5):379-384

33. El-Ansary A, Ben Bacha AG, Al-Ayahdi LY: Plasma fatty acids as diagnostic markers in autistic patients from Saudi Arabia. Lipids Health Dis 2011 $10: 62$.

34. Wiest MM, German JB, Harvey DJ, Watkins SM, Hertz-Picciotto I: Plasma fatty acid profiles in autism: a case-control study. Prostaglandins Leukot Essent Fatty Acids 2009, 80(4):221-227.

35. Lu L: Clinical and animal studies of lipid-derived protein modifications in autism, kidney dialysis, keratitis and age-related macular degeneration. PhD thesis, Department of Chemistry Department: Case Western Researve University; 2007.

36. Singh VK: Phenotypic expression of autoimmune autistic disorder (AAD): a major subset of autism. Ann Clin Psychiatry 2009, 21(3):148-161.

37. Connolly AM, Chez MG, Pestronk A, Arnold ST, Mehta S, Deuel RK: Serum autoantibodies to brain in Landau-Kleffner variant, autism, and other neurologic disorders. J Pediatr 1999, 134:607-613.

38. Vojdani A, Campbell AW, Anyanwu E, Kashanian A, Bock K, Vojdani E: Antibodies to neuron-specific antigens in children with autism: possible cross-reaction with encephalitogenic proteins from milk, Chlamydia pneumoniae and Streptococcus group A. J Neuroimmunol 2002, 129(1-2):168-177.

39. Steinke JW, Kennedy JL: Leukotriene Inhibitors in Sinusitis. Curr Infect Dis Rep 2012, In press.

40. Wu Y, He C, Gao Y, He S, Liu Y, Lai L: Dynamic modeling of human 5-lipoxygenase-inhibitor interactions helps to discover novel inhibitors. J Med Chem 2012, 55(6):2597-2605.

41. Muskiet FAJ: Pathophysiology and Evolutionary Aspects of Dietary Fats and Long-Chain Polyunsaturated Fatty Acids across the Life Cycle. In Fat Detection: Taste, Texture, and Post Ingestive Effects. Boca Raton (FL). Edited by Montmayeur JP, Le C.: CRC Press; 2010. Chapter 2. Frontiers in Neuroscience.

42. Abu Shmais GA, Al-Aydhi L, Al-Dbass A, El-Ansary A: Mechanism of nitrogen metabolism-related parameters and enzyme activities in the pathophysiology of autism. J Neurodev Disord 2012, doi:10.1186/ 1866-1955-4-4.

43. Baron-Cohen $S$, Ring R, et al: The amygdale theory of autism. Neurosci Biobehav Rev 2000, 24(3):355-364.

44. Lozinsky S: Misoprostol elevates intracellular calcium levels and increases glutamate release in type-l astrocytes: Implication in autism, Master thesis. Toronto Ontario: York University; 2010.

45. Libbey JE, Sweeten TL, McMahon WM, Fujinami RS: Autistic disorder and viral infections. J Neurovirol 2005, 11(1):1-10

46. Manzardo AM, Henkhaus R, Dhillon S, Butler MG: Plasma cytokine levels in children with autistic disorder and unrelated siblings. Int I Dev Neurosci 2012, 30(2):121-127.

47. Wei H, Chadman KK, McCloskey DP, Sheikh AM, Malik M, Brown WT, Li X: Brain IL-6 elevation causes neuronal circuitry imbalances and mediates autism-like behaviors. Biochim Biophys Acta 2012, 1822(6):831-842.

48. Wei H, Zou H, Sheikh AM, Malik M, Dobkin C, Brown WT, Li X: IL-6 is increased in the cerebellum of autistic brain and alters neural cell adhesion, migration and synaptic formation. J Neuroinflammation 2011, 8:52.

49. Auyeung B, Baron-Cohen S, Ashwin E, Knickmeyer R, Taylor K, Hackett G: Fetal testosterone and autistic traits. Brit J Psychol (London, England 1953, 100(1):1-22

50. James WH: Further evidence that some male-based neurodevelopmental disorders are associated with high intrauterine testosterone concentrations. Dev Med Child Neurol 2008, 50(1):15-18. 
51. Geier D, Geier M: A clinical trial of combined anti-androgenand antiheavy metal therapy in autistic disorders. Neuro Endocrinol Lett 2006, 27(6):833-838.

52. Geier D, Geier M: A prospective assessment of androgen levels in patients with autistic spectrum disorders: biochemical underpinnings and suggested therapies. Neuro Endocrinol Lett 2007, 28(5):565-573.

53. Tordjman S, Ferrari P, Sulmont V, Duyme M, Roubertoux P: Androgenic activity in autism. Am J Psychiatry 1997, 154:1626-1627.

54. Dean S: Regulation of cerebellar estradiol synthesis and Purkinje cell morphology by prostaglandins: Implications for neurodevelopmental disease. Baltimore: University of Maryland; 2009.

55. Rangel-Huerta OD, Aguilera CM, Mesa MD, Gil A: Omega-3 long-chain polyunsaturated fatty acids supplementation on inflammatory biomakers: a systematic review of randomised clinical trials. Br J Nutr 2012, 107(2):S159-S170.

doi:10.1186/1476-511X-11-160

Cite this article as: El-Ansary and Al-Ayadhi: Lipid mediators in plasma of autism spectrum disorders. Lipids in Health and Disease 2012 11:160.

\section{Submit your next manuscript to BioMed Central and take full advantage of:}

- Convenient online submission

- Thorough peer review

- No space constraints or color figure charges

- Immediate publication on acceptance

- Inclusion in PubMed, CAS, Scopus and Google Scholar

- Research which is freely available for redistribution 